The main text, however, is correct (as are the supplementary figures), and this oversight does not change the conclusions of this analysis.

The errors have now been rectified, and the correct article appears in this issue. The html and online pdf versions have also been rectified, and now carry the correct paper (including the corrected Supplementary Table 6, which now presents the correct statistics for the $t$-tests and ANOVA).

The authors would like to apologise for any inconvenience this may have caused.

\title{
Natural occurrence of microbial sulphur oxidation by long-range electron transport in the seafloor
}

Sairah Y Malkin, Alexandra MF Rao, Dorina Seitaj, Diana Vasquez-Cardenas, Eva-Maria Zetsche, Silvia Hidalgo-Martinez, Henricus TS Boschker and Filip JR Meysman

The ISME Journal (2014) 8, 2551-2552. doi:10.1038/ismej.2014.170

Correction to: The ISME Journal (2014) 8, 1843-1854; doi:10.1038/ismej.2014.41; published online 27 March 2014

Since the publication of this article, the authors have identified an error within Figure 2, namely that two accession numbers for the clones in panel $\mathrm{d}$ (a phylogenetic tree) were incorrect.

The correct accession numbers are Aarhus (JX091070.1) and Aarhus (JX091067.1), and the correct figure is shown below.

The Authors would like to apologise for any inconvenience this may have caused. 

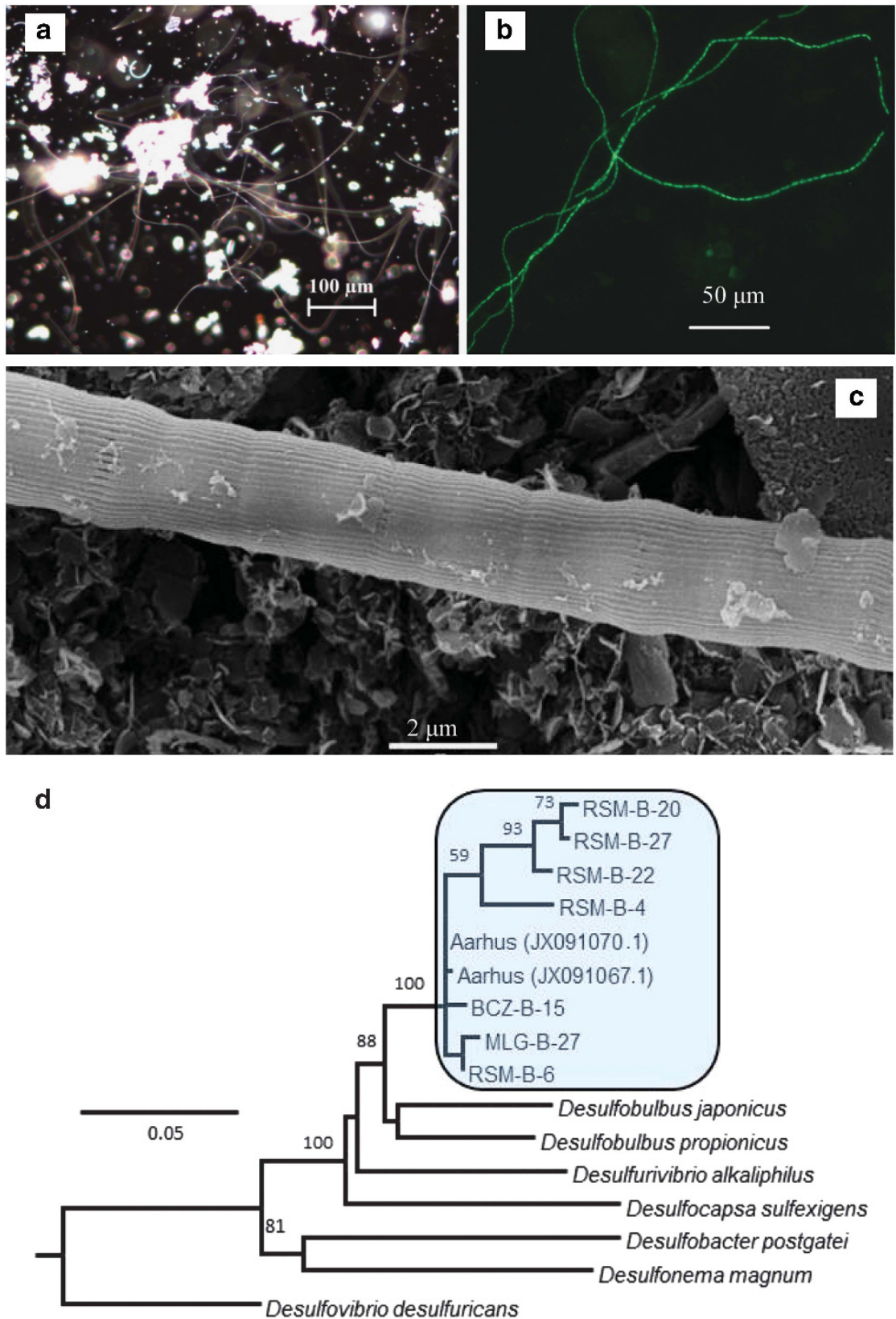

Figure 2 Identification of filamentous Desulfobulbaceae bacteria present in intact sediment from sites described in Figure 1 and Table 1. (a) Abundant long filamentous bacteria taken from near the surface of sediment and gently teased apart with forceps. (b) Identification of the filaments belonging to Desulfobulbaceae using CARD-FISH (DSB 706 probe). (c) SEM image of a bacterial filament isolated from the sediment. All images shown here are from MLG. See Supplementary material for images from RSM and BCZ. (d) Phylogenetic tree of Desulfobulbaceae 16S rRNA sequences recovered from intact sediment described in Figure 1. Closely related sequences of filamentous. Desulfobulbaceae from Aarhus Bay and other isolated bacteria are also included. Scale bar shows 5\% sequence divergence and bootstrap support is indicated on tree branches. 